\title{
A REVIEW ON CATABOLIC ACTIVITY OF MICROORGANISMS IN
} LEATHER INDUSTRY

\author{
MERAL BIRBIR, PINAR CAGLAYAN \\ Marmara University, Faculty of Arts and Sciences, Biology Department, Istanbul,Turkey, \\ *Corresponding Author: mbirbir@marmara.edu.tr
}

\begin{abstract}
A tremendously diverse group of microorganisms originated from animal skins/hides, animals' feces, preservation salt, dust, barn, water, air, soil, feed have been found on salted hides/skins. Growth and catabolic activities of these microorganisms have been supported by high organic and inorganic contents of salted hides/skins. As known, detail examination of catabolic activities of microorganisms offers an important information about their critical roles on hide/skin biodegradation. The goal of this review is to summarize experimental results of the previous studies to understand biodegradation capabilities of the microorganisms isolated from leather industry. Catabolic activities of microorganisms belonging to non-halophilic bacteria, moderately halophilic bacteria, extremely halophilic archaea and the members of family Enterobacteriaceae were summarized in the present study. The characterization of these microorganisms was performed according to molecular methods, conventional biochemical tests in the previous studies. Examination of research articles showed that aerobic microorganisms isolated from salted hides/skins produced protease, caseinase, lipase, $\beta$-galactosidase, amylase, cellulase, DNase, lecithinase and urease. Moreover, the isolates produced acid from different carbon sources, reduced nitrate to nitrite, produced $\mathrm{NH}_{3}$ from peptone, decarboxylated different amino acids found in hides/skins. These studies demonstrated that salted hides/skins had a wide diversity of microorganisms which have different catabolic activities to breakdown carbon and energy sources for their growth.
\end{abstract}

Keywords: Bacteria, Archaea, Leather industry

\section{INTRODUCTION}

Skin is composed of water $(64 \%)$, fats $(2 \%)$, structural proteins $(29 \%$ collagen, $2 \%$ keratin, $0.3 \%$ elastin), non-structural proteins ( $1 \%$ albumins and globulins, $0.7 \%$ mucins and mucoids), mineral salts $(0.5 \%)$, other substances $(0.5 \%)$ (Highberger, 1956; Hien, 2006). Freshly slaughtered skins are an ideal growth supporting organic medium for microbial cells which made up water, nucleic acids, proteins, polysaccharides, and fats. Presence of different of microorganisms on cattle hides, sheep and goat skins was detected by researchers and their high prevalence on hides and skins were related to high nutritional content of hides and skins. While some of these microorganisms are related to normal microbial flora of the animal hides and skins, the others may be contaminant microorganisms found in the air, water, soil, pasture, animal feeds, animal feces, barn, slaughterhouse, and tanneries (Sverre, 1956; Birbir and Ilgaz, 1996; Ulusoy and Birbir, 2015). When the animal is alive, growth of these contaminant microorganisms have been prevented by acidic $\mathrm{pH}$ of the hides/skins as well as normal microbial flora of the animals. After flaying process, these microorganisms release different enzymes to break down proteins, fats and carbohydrates into their building blocks for their carbon, nitrogen, hidrogen, and the other needs to grow. Hence, hides and skins are salted to prevent the growth and damage of these non-halophilic microorganisms but preservation salt contaminates hides and skins with extremely halophilic archaea, halotolerant, slightly halophilic and moderately halophilic bacteria. 


\section{NON-HALOPHILIC BACTERIA ON HIDES AND SKINS}

In the study of Venkatesan and colleagues (1970), non-halophilic protease positive Achromobacter liquefaciens, Alcaligenes marshalli, Bacillus cereus, Bacillus circulans, Bacillus megatherium, Bacillus pantothenticus, Bacillus subtilis, Brevibacterium insectiphilum, Micrococcus roseus and Staphylococcus aureus were isolated from three fresh goat skins obtained from India. After 24 hours curing process of the goat skins, nonhalophilic protease positive Alcaligenes marshalli, Bacillus cereus, Bacillus megaterium, Bacillus subtilis, Kurthia variabilis, Micrococcus rubens, Staphylococcus aureus were isolated.

Twenty-one isolates of Bacillus cereus (4), Bacillus megaterium (2), Bacillus sphaericus (3), Bacillus subtilis (7), Kurthia variabilis (1), Micrococcus roseus (2), Staphylococcus aureus (2) were isolated from newly slaughtered 10 fresh cattle hides collected from slaughterhouse in Istanbul, Turkey. All Bacillus species, two Staphylococcus aureus species ( $86 \%$ of the isolates) were able to digest gelatin. We detected that $81 \%, 62 \%, 81 \%, 10 \%, 52 \%$ of the isolates respectively produced urease, amylase, reduced nitrate to nitrite, produced indol from tryptophan, produced acetoin from glucose (Birbir and Ilgaz, 1996).

Sixty-six bacterial isolates of Bacillus brevis (2), Bacillus cereus (8), Bacillus licheniformis (3), Bacillus megaterium (2), Bacillus pumilus (3), Bacillus sphaericus(5), Bacillus subtilis (10), Kurthia variabilis (3), Micrococcus candidus (1), Micrococcus luteus (10), Micrococcus roseus (3), Micrococcus rubens (6), Staphylococcus aureus(7) and Staphylococcus epidermidis (3) were obtained from one week old 15 salted cattle hides collected from tanneries of Turkey. High catabolic activities and different bacterial species were detected at salted hides compare to the fresh cattle hides. Proteolytic activities were observed in all Bacillus species, all isolates of Micrococcus roseus, Staphylococcus aureus and Staphylococcus epidermidis. While 56\% of the isolates reduced nitrate to nitrite and produced urease enzyme, $46 \%, 32 \%$ and $5 \%$ of the isolates produced amylase, the neutral product acetoin from glucose, and indol from tryptophan, respectively (Birbir and Ilgaz, 1996).

Furthermore, 71 isolates of Bacillus cereus (3), Bacillus firmus (1), Bacillus licheniformis (4), Bacillus megaterium (7), Bacillus pumilus (4), Bacillus sphaericus(8), Bacillus subtilis (24), Kurthia variabilis (1), Micrococcus candidus (1), Micrococcus luteus (5), Micrococcus roseus (6), Micrococcus rubens (3), Staphylococcus aureus(3) and Staphylococcus epidermidis (1) were isolated from two months old 25 salted cattle hides. Proteolytic activities (96\% of the isolates) were observed in all Bacillus species, all isolates of Micrococcus luteus, Micrococcus roseus and Staphylococcus aureus and all isolates of Staphylococcus epidermidis, Kurthia variabilis,Micrococcus candidus. While $79 \%$ and 90 of the isolates respectively reduced nitrate to nitrite and produced urease enzyme, $65 \%, 49 \%, 8 \%$ of the isolates produced amylase, acetoin from glucose, and indol from tryptophan, respectively. Epidermis, dermis and hipodermis layers and collagen fibers of the hides were damaged by bacterial attack (Birbir and Ilgaz, 1996).

In another study, 256 non-halophilic Gram-negative bacterial isolates of Acinetobacter baumannii (3), Acinetobacter calcoaceticus (2), Acinetobacter haemolyticus (1), Acinetobacter junii ssp. johnsonii (5), Acinetobacter lwoffii (5), Aeromonas caviae (1), Aeromonas hydrophila (1), Alcaligenes faecalis (3), Burkholderia gladioli (7), Citrobacter amalonaticus (1), Citrobacter ferundii (3), Comamonas testesteroni (2), Edwardsiella tarda (1), Enterobacter aerogenes (4), Enterobacter agglomerans (4),Enterobacter amnigenus (12), Enterobacter cloacae (22), Enterobacter gergoviae (9), Enterobacter intermedius (4),

https://doi.org/10.24264/icams-2018.VI.3 
Enterobacter liquefaciens(3), Enterobacter sakazakii (8), Escherichia coli(9), Hafnia alvei(14), Klebsiella oxytoca (1), Klebsiella pneumoniae ssp. ozanae (1), Mannheimia haemolytica (3), Pasteurella multocida (4), Pasteurella pneumotropica (5), Proteus mirabilis (1), Pseudomonas aeruginosa (1), Pseudomonas fluorescens (9), Pseudomonas luteola (29), Pseudomonas maltophila (2), Pseudomonas paucimobilis (1), Pseudomonas pseudoalcaligenes (1), Pseudomonas putida (16), Salmonella choleraesuis ssp. arizonae (1), Salmonella paratyphi A (1), Salmonella typhimurium (1), Serratia marcescens (1), Sphingomonas paucimobilis (5), Stenotrophomonas maltophila (12), Vibrio fluvialis (27), Vibrio vulnificus (5), Yersinia pseudotuberculosis (1), Yersinia ruckeri (4) were isolated from ten salted hides cured in England, Australia and Turkey (Aslan and Birbir, 2012).

Moreover, 396 Gram-positive bacteria such as Aerococcus urinae (5), Aerococcus viridans (24), Aneurinibacillus aneurinilyticus (4), Bacillus amyloliquefaciens (3), Bacillus cereus (3), Bacillus firmus (8), Bacillus laterosporus (1), Bacillus lentus (15), Bacillus licheniformis (16), Bacillus megaterium (10), Bacillus mycoides (4), Bacillus pumilus (20), Bacillus subtilis (14), Bacillus thuringiensis (17), Brevibacillus laterosporus (2), Enterococcus avium (17), Enterococcus casseliflavus (3), Enterococcus durans (6), Enterococcus faecalis (12), Enterococcus faecium (14), Enterococcus gallinarum (23), Geobacillus stearothermophilus (3), Geobacillus thermoglucosidiasius (3), Kocuira kristanea (4), Kocuira varians (4), Lactococcus lactis (13), Paenibacillus pabuli (3), Streptococcus acidominimus (13), Streptococcus bovis (2), Streptococcus pluranimalium (4), Streptococcus thermophilus (1), Streptococcus uberis (7), Staphylococcus aureus (7), Staphylococcus capitis (15), Staphylococcus caprae(2), Staphylococcus chromogenes(2),Staphylococcus cohnii (17), Staphylococcus epidermidis (1), Staphylococcus hominis (9), Staphylococcus hyicus (7), Staphylococcus intermedius (32), Staphylococcus lentus (1), Staphylococcus lugdunensis (3), Staphylococcus sciuri (3), Staphylococcus xylosus (15), Staphylococcus warneri (1), Virgibacillus panthothenticus (3) were isolated (Aslan and Birbir, 2011). While $68 \%, 52 \%, 43 \%$ of Gram-negative bacterial isolates and $70 \%, 69 \%$ and $57 \%$ of the Gram-positive bacterial isolates demonstrated respectively proteolytic, lipolytic and both proteolytic and lipolytic activities (Aslan and Birbir, 2012;Aslan and Birbir, 2011).

\section{Extremely Halophilic Archaea and Moderately Halophilic Bacteria on Salted Hides and Skins}

Kallenberger (1985) stated that halophilic microorganisms found in curing salt contaminate hides and skins. Examination of 131 brine-cured cattle hides collected from USA showed that $94 \%$ of salted hide samples were contaminated with extremely halophilic archaea (Bailey and Birbir, 1993). Fifty three percent of these extremely halophilic archaea showed protease activities. When 35 salted hides cured in France and Russia were examined, it was observed that $29 \%, 37 \%, 86 \%, 91 \%$ of the samples respectively contained halotolerant, slightly halophilic, moderately halophilic bacteria, and extremely halophilic archaea (Birbir, 1997).

In the study of Akpolat et al. (2015), 101 extremely halophilic archaea such as Halorubrum tebenquichense (54), Halorubrum saccharovorum (24), Halorubrum lipolyticum (1), Halorubrum kocurii (1), Halorubrum terrestre (1), Halococcus morrhuae (2), Halococcus dombrowskii (9), Halococcus qingdaonensis (3), Natrinema versiforme (1), Natrinema pellirubrum (3), Halostagnicola larsenii (1), Haloterrigena saccharevitans (1) were isolated from salted sheep skins collected from Spain. Proteolytic and lipolytic activities of these isolates were detected as $15 \%$ and 5\%. 
In a study carried out with salted cattle hides imported from Australia and England, 13 moderately halophilic bacteria such as Alkalibacillus salilacus, Salimicrobium album, Salimicrobium halophilum, Salimicrobium luteum, Marinococcus halophilus, Halomonas koreensis, Halomonas alimentaria, Halomonas elongata, Halomonas halmophila, Halomonas eurihalina, Thalassobacillus devorans, Chromohalobacter salexigens, Oceanobacillus picturae and five extremely halophilic archaeal species such as Halorubrum saccharovorum, Halorubrum tebenquichense, Halorubrum lacusprofundi, Natrinema pallidum and Natrinema gari were isolated from these hides. Amylase, protease, lipase, caseinase, urease, pullulanase and DNase activities of the moderately halophilic isolates were respectively detected as $15 \%, 31 \%, 15 \%, 15 \%$, $31 \%, 8 \%, 38 \%$. Amylase, protease, urease, DNase activities of the extremely halophilic isolates were detected as $20 \%$. In addition, $54 \%, 77 \%, 54,38,15$ of the moderately halophilic isolates and $40 \%, 60 \%, 40 \%, 20 \%, 20 \%$ of the extremely halophilic archaeal isolates respectively used citrate as a sole carbon source, reduced nitrate to nitrite, produced acid from glucose, sucrose and lactose (Caglayan et al., 2015).

In a study of Bilgi et al. (2015), 186 extremely halophilic archaea were isolated from eight salted hides and skins cured in Turkey, Iraq, Turkmenistan, Kazakhstan and Armenia. Isolation of extremely halophilic archaeal isolates of Natronococcus sp., Natronococcus jeotgali, Natrialba aegyptia, Halovivax sp. E107, Halovivax asiaticus, Halococcus morrhuae, Halococcus thailandensis, Halococcus dombrowskii, Halorubrum sp. CH3, Natrinema pallidum, Natrinema versiforme, Haloterrigena thermotolerans, Halobacterium noricense was stated by researchers. While all isolates had DNase activities, $12 \%, 57 \%, 11 \%, 35 \%, 18 \%$ of the isolates showed positive reactions for caseinase, protease, amylase, esterase, lipase activities. Moreover, it was detected that $8 \%$ and $62 \%$ of the isolates produced indole from tryptophan and reduced nitrate to nitrite.

In addition, 39 bacterial isolates of moderately halophilic bacteria such as Staphylococcus saprophyticus subsp. saprophyticus (7), Staphylococcus xylosus (2), Staphylococcus equorum subsp. equorum (1), Staphylococcus arlettae (6), Bacillus pumilus (6), Bacillus licheniformis (2), Salinicoccus roseus (3), Gracilibacillus dipsosauri (5), Chromohalobacter beijerinckii (2), Chromohalobacter canadensis (1), Halomonas eurihalina (2), Halomonas zhanjiangensis (1), Halomonas venusta (1) were isolated from 25 goat skins cured in Bulgaria, Israel, China, Australia, South Africa, Russia, France and Turkey. Protease, lipase, $\beta$-galactosidase, urease, caseinase, amylase, lecithinase, cellulase activities of the isolates were detected as $87 \%, 64 \%$, 59\%, 46\%, 28\%, 26\%, 8\% and 5\% (Birbir et al., 2015; Caglayan et al., 2017). Indole production from tryptophan, citrate utilization, hydrogen sulfide $\left(\mathrm{H}_{2} \mathrm{~S}\right)$, reduction of nitrate to nitrite, ammonia production from peptone by the isolates were respectively detected as $3 \%, 31 \%, 5 \%, 51 \%, 85 \%$. Moreover, acid production from glucose, sucrose, galactose, mannose by the isolates were found as $92 \%, 85 \%, 56 \%, 74 \%$, respectively.

In a study of Caglayan et al. (2017), 77 bacterial isolates of moderately halophilic bacteria such as Staphylococcus equorum subsp. equorum (4), Staphylococcus cohnii subsp. cohnii (3), Staphylococcus xylosus (2), Staphylococcus lentus (2), Staphylococcus saprophyticus subsp. saprophyticus (1), Salimicrobium salexigens(4), Bacillus pumilus (2), Bacillus licheniformis (7), Bacillus safensis (2), Bacillus siamensis (1), Bacillus tequilensis (2), Salinicoccus roseus (2), Planococcus rifietoensis (1), Alkalibacillus halophilus (1), Gracilibacillus dipsosauri (4), Marinococcus luteus (1), Marinococcus tarijensis (1), Oceanobacillus picturae (1), Halomonas halmophila (5), Halomonas eurihalina (1), Halomonas zhanjiangensis (4), Halomonas venusta (2), Halomonas alkaliphila (3), 
Salinivibrio costicola subsp. alkaliphilus (4), Chromohalobacter canadensis (6), Chromohalobacter beijerinckii (6), Chromohalobacter japonicus (3), Chromohalobacter israelensis (1), Idiomarina loihiensis (1) were isolated from 23 salted sheep skins cured in Australia, Bulgaria, Dubai, Greece, Israel, Kuwait, South Africa, Turkey and U.S.A. Protease, lipase, $\beta$-galactosidase, amylase, caseinase, DNase, urease, cellulase, lecithinase activities of these isolates were respectively found as $60 \%, 43 \%, 39 \%, 26 \%, 23 \%, 17 \%$, $12 \%, 12 \%, 10 \%$. Indole production from tryptophan, citrate utilization, production of $\mathrm{H}_{2} \mathrm{~S}$, reduction of nitrate to nitrite, production of ammonia from peptone by the isolates were detected as $12 \%, 47 \%, 8 \%, 78 \%, 87 \%$, respectively. Acid production from glucose, sucrose, galactose, mannose by the isolates were found as $95 \%, 71 \%, 78 \%, 90 \%$.

Utilization of different amino acids found in the skin by 137 moderately halophilic bacterial species belonging to genera Halomonas, Planococcus, Salimicrobium, Alkalibacillus,Salinicoccus,Staphylococcus, Bacillus, Chromohalobacter, Gracilibacillus, Idiomarina,Marinococcus, Oceanobacillus, Salinivibrio was investigated. Arginine was used by all moderately halophilic isolates obtained from the salted goat and sheep skins. L-hydroxyproline, L-proline, L-tyrosine, L-alanine, L-glycine amino acids were respectively utilized by $66 \%, 64 \%, 85 \%, 66 \%, 86 \%$ of the isolates but L-cysteine was used only $4 \%$ of the isolates. These results showed that salted sheep and goat skin isolates were able to utilize L-hydroxyproline, L-proline, L-tyrosine, L-alanine, Lglycine and L-cysteine amino acids found in the skin structure Caglayan et al. (2018).

\section{Bacterial Species of the Family Enterobacteriaceae on the Salted Hides and Skins}

In the other study, Ulusoy and Birbir (2015) examined members of the family Enterobacteriaceae on the salted hides and skins. While 27 isolates of Enterobacter cloacae (2), Enterobacter sakazakii (1), Raoultella planticola (1), Raoultella ornithinolytica (1), Serratia odorifera (1), Serratia liquefacicens (1), Serratia plymuthica (1), Serratia rubidaea (3), Escherichia coli (2), Escherichia vulneris (1), Cedecea lapagei (3), Ewingella americana (2), Klebsiella pneumoniaea ssp. ozaenae (1), Klebsiella oxytoca (2), Proteus vulgaris (2), Yersinia enterocolitica (3) were obtained from the hides salt cured in Dubai, Turkey and Israel and 28 isolates of Citrobacter koseri (1), Enterobacter cloacae (2), Escherichia coli (4), Escherichia vulneris (1), Klebsiella pneumoniaea ssp. ozaenae (1), Klebsiella oxytoca (1), Proteus vulgaris (2), Proteus penneri (1), Raoultella planticola (1), Serratia odorifera (1), Serratia liquefacicens (1), Serratia plymuthica (3), Serratia ficaria (1), Serratia marcescens (2), Serratia rubidaea (4), Yersinia enterocolitica (2) were obtained from the skin samples salt cured in Australia, Lebanon, U.S.A., South Africa. Protease, urease, $\beta$-galactosidase, lipase activities of the isolates were respectively found as $45 \%$, $35 \%, 90 \%, 30 \%$. Moreover, $25 \%, 35 \%, 35 \%, 45 \%, 35 \%, 70 \%$ of the isolates respectively were found to be positive for tryptophan deaminase, arginine dihydrolase, ornithine decarboxylase, lysine decarboxylase, indol production, utilization of citrate. While all isolates produced acid from glucose, $75 \%, 70 \%, 90 \%$ of the enteric isolates produced acid from sucrose, arabinose, mannitol, respectively.

\section{CONCLUSIONS}

All of these studies carried out fresh, salted hides and skins clearly showed that nonhalophilic bacteria, moderately halophilic bacteria, extremely halophilic archaea and bacterial species of the family Enterobacteriaceae were metabolically active to degrade 
proteins, fats, carbohydrates and use their building blocks for their nutritional and structural needs, growth and energy. While most of the examined hides and skin samples had bad odor and red, yellow, cream discolorations, some of them had hair slip which were related to microbial activities. These experimental study results clearly demonstrated that most of the organisms found on the skins and hides were belong to contaminant microorganisms found in the air, water, soil, curing salt, pasture, animal feeds, animal feces, barn, slaughterhouse, and tanneries. These studies also showed that traditional salt curing process does not prevent the growth of these different species of microorganisms causing huge economic losses in leather industry. Hence, we suggest using effective antimicrobial applications to exterminate these hide and skin degrading microorganisms in the leather industry.

\section{REFERENCES}

Akpolat, C. et al. (2015), "Molecular Identification of Moderately Halophilic Bacteria and Extremely Halophilic Archaea Isolated from Salted Sheep Skins Containing Red and Yellow Discoloratios", The Journal of the American Leather Chemists Association, 110, 211-220.

Aslan, E. and Birbir, M. (2011), "Examination of Gram-Positive Bacteria on Salt-Pack Cured Hides", The Journal of the American Leather Chemists Association, 12(106), 372-380.

Aslan, E. and Birbir, M. (2012), "Examination of Gram-Negative Bacteria on Salt-Pack Cured Hides", The Journal of the American Leather Chemists Association, 4(107), 106-115.

Bailey, D.G. and Birbir, M. (1993), "A Study of the Extremely Halophilic Microorganisms Found on Commercially Brine-Cured Cattle Hides", The Journal of the American Leather Chemists Association, 88, 285-293.

Bilgi, S.T., Yapici, B.M. and Karaboz, I. (2015), "Determination of Hydrolytic Enzyme Capabilities of Halophilic Archaea Isolated from Hides and Skins and Their Phenotypic and Phylogenetic Identification", The Journal of the American Leather Chemists Association, 110, 33-42.

Birbir, M. and Ilgaz, A. (1996), "Isolation and Identification of Bacteria Adversely Affecting Hide and Leather Quality", Journal of the Society of Leather Technologists and Chemists, 80, 147-153.

Birbir, M. (1997), "Investigation of Salt-cured France and Russian Hides for Halophilic Bacteria", Journal of Turkish Microbiology Society, 27, 68-73.

Birbir, M., Ventosa, A. and Caglayan, P. (2015), "Characterization of Moderately Halophilic Bacteria Found on the Sheep and Goat Skins", The Scientific Research Project Commission of Marmara University, Project Number FEN-C-DRP-040712-0281.

Caglayan, P. et al. (2015), "Characterization of Moderately Halophilic Bacteria from the Salt-pack Cured Hides", Journal of the Society of Leather Technologists and Chemists, 5, 250-254.

Caglayan, P. et al. (2017), "Screening of Industrially Important Enzymes Produced by Moderately Halophilic Bacteria Isolated from Salted Sheep Skins of Diverse Origin", The Journal of the American Leather Chemists Association, 112(6), 207-216.

Caglayan, P. et al. (2018), "Investigation of Moderately Halophilic Bacteria Causing Deterioration of The Salted Sheep and Goat Skins and Their Extermination via Electric Current Applications", The Journal of the American Leather Chemists Association, 113(2), 41-52.

Hien, N.T.P. (2006), "A Rapid Quantitative Assay for Bacterial Protease Activity", Master Thesis, The Graduate Faculty of Texas Tech University.

Highberger, H.J. (1956), "The Chemical Structure and Macromolecular Organization of the Skin Proteins", in: O'Flaherty, F., Roddy, W.T., Lollar, R.M. (eds.), The Chemistry and Technology of Leather, Reinhold Publishing Corporation, New York, 1, 65-193.

Kallenberger, W.E. (1985), "Halophilic Bacteria in Hide Curing", PhD Thesis, Division of Graduate Studies and Research of the University of Cincinati, Department of Basic Science Tanning Research of the Collage of Arts and Science.

Sverre, D. (1956), "Prevention of Microbial Deterioration of Leather", The Journal of the American Leather Chemists Association, 51,113-117.

Ulusoy, K. and Birbir, M. (2015), "Identification and Metabolic Activities of Bacterial Species Belonging to the Enterobacteriaceae on Salted Cattle Hides and Sheep Skins", The Journal of the American Leather Chemists Association, 110, 86-199.

Venkatesan, R.A., Nandy, S.C. and Sen, S.N. (1970), "Effect of Storage and Pretanning Operations on the Bacterial Flora and Its Population on Goat Skin", Leather Science, 17, 395-404.

https://doi.org/10.24264/icams-2018.VI.3 